\title{
TIL Research
}

National Cancer Institute

\section{Source}

National Cancer Institute. TIL Research. NCI Thesaurus. Code C15962.

Research on tumor-infiltrating lymphocytes and their use as a cancer treatment. 